\title{
Linguistic Sequence Processing and the Prefrontal Cortex
}

\author{
Ina Bornkessel-Schlesewsky ${ }^{* 1}$ and Matthias Schlesewsky ${ }^{2}$ \\ ${ }^{I}$ Department of Germanic Linguistics, University of Marburg, Marburg, Germany \\ ${ }^{2}$ Department of English and Linguistics, Johannes Gutenberg-University, Mainz, Germany
}

\begin{abstract}
Since language necessarily unfolds over time, language comprehension involves the processing of a sequentially ordered input. In this paper, we review neuroimaging findings on syntactic processing and word order variations in order to shed light on the neural bases of linguistic sequencing, focusing particularly on the role of prefrontal cortex (including Broca's region). On the basis of the full range of available data from several languages, we argue that different types of sequencing cues correlate with activation along an anterior-posterior gradient in frontal cortex, with highly local sequencing cues eliciting activation in the most posterior frontal regions (premotor cortex and the cytoarchitectonically corresponding frontal operculum) and less local sequencing cues (requiring relational comparisons between the current input element and the current sentence or discourse context, respectively) engendering activation in successively more anterior regions of the left inferior frontal gyrus. We argue that this neurocognitive gradient of linguistic sequence processing can be associated with a more general hierarchy of cognitive control in prefrontal cortex, which has also been shown to vary along an anterior-posterior gradient [1]. We conclude that the processing of linguistic sequences and the concomitant extraction of information (e.g. semantic relations) from them, as an essential component of language processing, follows more general principles of neurocognitive organisation in prefrontal cortex.
\end{abstract}

Keywords: Language processing, word order, sequencing, syntax, cognitive control, inferior frontal gyrus, premotor cortex, Broca's region.

\section{INTRODUCTION}

Whether it is spoken, written or signed, a linguistic utterance unfolds in time. Accordingly, the information which it conveys changes from moment to moment, depending on which parts of the utterance have already been encountered and which are yet to come. As a result of this intimate relation between language and time, the order in which the words in a sentence are encountered is of crucial importance to the way in which that sentence can be understood: order or sequence information is a cue that a hearer "gets for free" in any language. Importantly, in addition to specifying the linear precedence relation between two elements (e.g. words in a sentence), their sequential position can be used to construct a hierarchical syntactic structure (e.g. [2], for a theoretical approach; and [3], for a description of suitable parsing algorithms). In view of these observations, it is not surprising that sequence information has played an exceptionally important role in the study of language understanding; for example, a wide range of proposals has been put forward with regard to how a word that is encountered in a particular position in a sentence contributes to the establishment of sentence meaning in real time.

Interestingly, however, and in spite of the fact that sequencing information is always available, not all languages adhere to a rigid word order. Indeed, English is an exception in this regard rather than the rule: the majority of languages show at least some degree of word order flexibility [4]. Thus,

*Address correspondence to this author at the Department of Germanic Linguistics, University of Marburg, Wilhelm-Roepke-Strasse 6A, 35032 Marburg, Germany; Tel: +49 - (0)6421 - 2824675; Fax: +49 - (0)6421 2824558; E-mail: iboke@staff.uni-marburg.de beyond the fundamental question of how the human brain processes linguistic sequences, the cross-linguistic perspective raises an additional crucial point, namely how it deals with linguistic sequences when there is more than one possible ordering of the elements relative to one another.

The aim of the present paper is to review cross-linguistic neuroimaging findings on the cognitive and neural bases of linguistic sequencing. ${ }^{1}$ Since the processing of word order has often been associated with Broca's region, i.e. the pars opercularis (POp) and pars triangularis (PTr) of the left inferior frontal gyrus (IIFG), a substantial part of the discussion will focus on this cortical region. Furthermore, since many studies in the neuroimaging literature on language have used word order processing as a diagnostic for syntactic processes more generally, the relationship between "sequencing" and "syntax" will also concern us here. In particular, we will focus on two central questions:

(a) How is sequencing used as a cue to the establishment of a hierarchical syntactic structure?

(b) How are flexible sequencing requirements processed?

We will argue that, though some recent approaches to the neural bases of syntactic processing have suggested otherwise, these two aspects of sequencing are closely intertwined and can be viewed as instances of a single underlying cognitive process which operates upon different information types. From a more general cognitive perspective, we will suggest that these information sources translate into cogni-

\footnotetext{
${ }^{1}$ Note that, in view of the focus on sequencing, a review of the complete neuroimaging literature on syntactic processing is beyond the scope of this paper.
} 
tive control cues of varying degrees of locality, the processing of which is implemented within a gradient along the anterior-posterior dimension of frontal cortex [1,5] (for an application to language processing, see [6]). From these observations and assumptions, we will conclude that the different levels of linguistic sequencing, as revealed by neuroimaging studies of language processing, constitute a powerful explanatory mechanism which not only lends itself to deriving the establishment of a hierarchical syntactic structure and the processing of flexible sequencing requirements (the two main questions raised above), but may also shed new light on the recent debate on recursion and the processing of human vs. non-human grammars [7-11]. Conversely, it also has important consequences for the functional interpretation of the neuroanatomical correlates of language.

The paper is organised as follows. In the next section, we first provide a brief review of the classic neuroimaging perspective on word order processing and Broca's region, which focused on "syntax" as an overarching concept. In section 3, we then discuss results which led to doubts as to whether syntactic processing as a whole can be effectively localised from a functional-neuroanatomical perspective and describe several theoretical proposals which are based upon this observation. Section 4 goes on to assess these accounts against cross-linguistic imaging results on the processing of word order variations in simple sentences. Finally, section 5 presents a new perspective on the neurocognitive bases of linguistic sequencing and section 6 offers some conclusions.

\section{THE TRADITIONAL VIEW: A COMMON NEURAL SUBSTRATE FOR WORD ORDER PROCESSING AND THE ESTABLISHMENT OF SYNTACTIC STRUCTURE?}

The earliest neuroimaging studies on syntax and sequencing were primarily conducted in English and were mainly concerned with the general question of how the brain processes syntactic information as opposed to other linguistic domains (e.g. semantics). Perhaps unsurprisingly, a substantial portion of the discussion in this regard focused on the role of Broca's region (i.e. the pars opercularis, POp, and pars triangularis, PTr, of the left inferior frontal gyrus, IIFG). Earlier patient studies on complex sentences had revealed a comprehension deficit for semantically reversible object relative clauses and object clefts in agrammatic (Broca's) aphasics [12]. ${ }^{2}$ Since this deficit did not extend to semantically irreversible sentences, it was hypothesised that these patients may have a specifically syntactic deficit. Thus, in contrast to the classic and longstanding neurolinguistic perspective that Broca's area is responsible for language production [17], it suddenly appeared attractive to associate this region with a particular linguistic domain, namely syntax.

Initial neuroimaging studies on word order in English appeared to support this conclusion. These studies used positron emission tomography (PET) or functional magnetic resonance imaging (fMRI) to examine the processing of

\footnotetext{
${ }^{2}$ Note that agrammatism / Broca's aphasia need not necessarily go hand-inhand with a lesion in Broca's region (e.g. $[13,14]$ ). However, the potential and enticing - link between the two continues to influence research in cognitive neuroscience (e.g. $[15,16])$.
}

object relative clauses, e.g. The reporter that the senator attacked admitted the error [18]. In contrast to typical English main clauses, which adhere to a subject-verb-object (SVO) order (The senator attacked the reporter), object relative clauses involve an object-subject-verb (OSV) order $\left(\right.$ that $_{\mathrm{O}}\left[\right.$ the senator $_{\mathrm{S}}$ attacked $\mathrm{V}$ ). They are thus associated with a different word order and, hence, different sequencing requirements to the majority of the sentences that the language comprehension system of an English native speaker processes [19]. In comparison to control sentences (e.g. subject relative clauses or conjoined active clauses), object relatives in English were shown to consistently engender activation in the IIFG (i.e. in the vicinity of classical Broca's region) $[18,20]$. These results are consistent with the assumption that Broca's region is responsible for the processing of syntactic information, since they can be interpreted as showing that a syntactically required deviation from the basic word order (in the case of English, a deviation from SVO), engenders increased activation in this region.

At first, this perspective appeared to receive support from further studies that examined slightly different manipulations. For example, Embick et al., [21] observed increased left inferior frontal activation for phrase structure violations (e.g. Bill wrote paper a about the discussion of the treaty) in comparison to orthographical violations (e.g. Bill wrote a papger about the discussion of the treaty). While other language-related areas (e.g. in temporal cortex) also showed increased activation for syntactic vs. orthographic errors, the difference was largest in Broca's area, thus leading the authors to argue for a syntactic specialisation of this region. A similar proposal was put forward by Moro et al., [22], who observed increased activation in Broca's area and in the basal ganglia for syntactic (determiner-noun order) violations in comparison to phonotactic violations in Italian. Thus, on the basis of these early studies, an initial conclusion would seem to be that the use of sequence information for the establishment of syntactic structures and the processing of word order requirements is supported by the same neural substrate. Indeed, some scholars continue to argue for a syntactic specialisation of the left POp and PTr, particularly on the basis of data from Japanese [23-26].

\section{DOUBTS REGARDING THE COMMON NEURAL SUBSTRATE VIEW}

In contrast to the experiments reviewed in section 2 , the results of other imaging studies cast doubt on the assumption that the IIFG can be viewed as a general locus for syntactic processing. For example, a series of experiments comparing the processing of sentences to that of word lists revealed activation in anterior temporal cortex (primarily leftlateralised) rather than in the IIFG [27-30]. Since sentences and word lists both require lexical processing, but only sentences require the establishment of a syntactic structure (as well as a range of further processes such as semantic composition), the conspicuous absence of IIFG activation in this comparison calls the importance of this region for syntactic processing into question [31]. In some of these studies, left frontal activation was in fact engendered by deviations from "normal sentences" (e.g. word lists [28], sentences involving pseudowords [30]), thus suggesting that the IIFG only steps in when language processing becomes 
more complex in some way (e.g. when working memory demands increase). In summary, there are a number of findings which raise questions about whether syntactic processing is indeed the best level of explanation / generalisation when considering the results in section $2 .^{3}$

The literature essentially contains two types of potential solutions to this problem. The first is to assume that the role of Broca's region (or even some of its subparts) in syntactic processing is more specific, i.e. pertains only to particular syntactic operations or to certain aspects of syntax. By contrast, the second type of approach proposes that the mechanisms in question are, in fact, broader than syntax and apply to a range of information types. We will discuss both types of approaches in turn in the following.

\subsection{Possible Solutions I: Syntax as too Broad}

A prominent proposal of the first type is due to Grodzinsky and colleagues, who suggest that Broca's region is responsible for the processing of syntactic movement, i.e. a very specific syntactic operation [15,34,35]. Recently, Santi and Grodzinsky [36, 37] argued for this position by directly comparing syntactic dependencies that either involved movement (wh-questions, relative clauses) or did not (binding). In [37], the comparison was undertaken via a $2 \times 2$ factorial design (see example 1).

(1) Example stimuli from [37]. Note that the underscore marks the "gap site", i.e. the base position of the wh-phrase (the "filler") which was "moved" to the beginning of the sentence.

(a) The girl supposes the cunning man hurt Christopher (-MOV, -BIND)

(b) The girl supposes the cunning man hurt himself (-MOV, +BIND)

(c) Which older man does Julia suppose hurt the child (+MOV, -BIND)

(d) Which older man does Julia suppose hurt himself (+MOV, +BIND)

Their results revealed a main effect of movement in the IIFG (Brodmann area, BA 44) ${ }^{4}$, the left superior temporal gyrus (STG) and the inferior portion of the left precentral sulcus. By contrast, a main effect of binding was observed in a more anterior and inferior portion of the IIFG (BA 45 / 47), right middle frontal and bilateral middle temporal regions as well as in the cingulate gyrus. Santi and Grodzinsky [37]

\footnotetext{
${ }^{3}$ Note that, by this discussion, we do not mean to imply that Broca's region is exclusively associated with the processing of the information types described here. There are now many studies showing that activation in this region correlates with the processing of a range of linguistic and nonlinguistic information types (for non-linguistic paradigms, see, for example, $[32,33])$. However, we restrict our discussion to the processing of syntactic information here in accordance with the paper's focus on linguistic sequencing.

${ }^{4}$ Here and in the following, we refer to Brodmann areas [38] rather than to macroscopic neuroanatomical regions (e.g. POp, PTr) whenever the studies under discussion only described Brodmann areas (BAs) in the discussion of their results. While an association between BA 44 and the POp and BA 45 and the PTri, respectively, is often assumed, note that this remains approximate at best because of individual cytoarchitectonic variability $[39,40]$
}

interpret these findings as evidence for a working memory (WM) system that is specific to syntactic movement.

In a second study, Santi and Grodzinsky [36] again compared movement and binding but, in contrast to their previous experiment, employed a parametric design. Using relative clauses rather than wh-questions (e.g. The mailman and the mother of Jim love the woman who Kate burnt [short distance between filler and gap], The mother of $\overline{\mathrm{Jim}}$ loves the woman who the mailman and Kate burnt [longer distance between filler and gap]), they manipulated the distance between filler and gap and between reflexive and antecedent, thus yielding three levels of complexity (distance) for each type of dependency. They again observed differential activation patterns for movement and binding. However, with the exception of the binding effect in the right middle frontal gyrus, the localisations of the previous study did not replicate: an effect of movement was observed in the anterior IIFG (BA 45), which had previously shown an effect of binding, and there was no left inferior frontal effect for binding. While Santi and Grodzinsky [36] again conclude "that Broca's area is specific to the WM needs of syntactic Movement rather than general to dependency relations" ( $p$. 16), at least in our view, the inconsistency of the results across the two studies calls into question the assumption of a movement-specific WM system ("module" in their terminology) in the 1IFG. ${ }^{5}$

Another proposal which views subparts of syntax as the crucial levels of generalisation for neuroanatomical localisation was advanced by Friederici and her colleagues [11,42, 43]. Building upon the observation that the likelihood for IIFG activation appears to increase whenever comprehension demands are high (rather than during "easy", commonplace syntactic processing; see above), Friederici proposes that the lateral convexity of the IIFG is involved in the processing of complex (hierarchical) syntax, while local syntactic structure building is accomplished by the deep frontal operculum

\footnotetext{
${ }^{5}$ The following passage from Santi and Grodzinsky [37] shows that these authors indeed assume a very precise localisation of individual "modules" within Broca's area rather than simply ascribing a single functional interpretation to the entire region:

While this study demonstrates that Broca's area has specificity, this does not mean that its functional role is exclusive to movement processing. Rather, it would appear from the empirical record that as Broca's area represents a large anatomical area, it houses multiple processing modules. Therefore, there could be a general WM module and a movement specific WM one, as well. ([37], p. 1096)

A further problem for the movement-specialisation approach arises in view of more recent findings by Santi and Grodzinsky [41]. Using an fMRIadaptation paradigm, they crossed "movement type" (subject vs. object in subject vs. object relative clauses) and type of embedding (centre embedded vs. right-branching) in a $2 \times 2$ design. Since anterior IIFG (BA 45) selectively adapted to movement type, the authors argue for a movement-specialisation of this region. However, in contradiction to previous publications by Grodzinsky and colleagues, the relevant distinction pertaining to movement is now one of canonicity, namely the contrast between "canonical" (subject) movement and "non-canonical" (object) movement. This distinction cannot be motivated with reference to any existing syntactic theory. It thus, in our view, illustrates the need to resort to ad hoc theoretical assumptions in order to attempt to maintain a movement-related interpretation of the role of (parts of) the IIFG in language processing. As also noted by Grodzinsky and colleagues in previous publications [35], both subject and object relative clauses involve (the same type of) movement. In fact, Ben-Shachar et al. [35] used this line of argumentation (p. 1334) to derive the fact that they did not find differential IIFG activation for object $v s$. subject wh-questions in Hebrew.
} 
(DFO), a structure deep to the lateral surface of the cortex. More specifically, she assumes that the processing of hierarchical syntax draws upon a "dorsal pathway" which connects the POp of the IIFG to the posterior portion of left superior temporal cortex, while local syntax is implemented in a "ventral pathway" which connects the deep frontal operculum to the anterior temporal lobe [43]. In this view, hierarchical syntax is thought to encompass the processing of recursive syntactic structures as well as the processing of word order variations at the sentence level (what we termed processing of flexible sequencing options in the introduction), while local syntax pertains primarily to the combination of elements (e.g. a determiner and a noun) at the phrasal level (i.e. essentially what we characterised as the use of sequence information to establish a syntactic structure in the introduction). With regard to the lateral convexity of the IIFG in comparison to the deep frontal operculum, this functional dissociation was first based on the comparison of imaging studies on word order permutations and syntactic violations, respectively [42]. While word order variations in flexible word order languages such as German consistently correlate with activation in the IIFG and particularly in the POp (e.g. [44-49]), local phrase structure violations (e.g. an incorrect word category within a phrase) appear to engender activation within the deep frontal operculum [30,50,51].

In order to further test this hypothesis, [11] presented participants with two different types of artificial grammars, one of which involved embedding (recursion) and one of which did not. Recursion involves self-embedding, i.e. the embedding of a particular syntactic category within an instance of the same category (e.g. a sentence within a sentence, as is the case with relative clause constructions such as The pony [that Patti likes to feed] is too fat; embedding of the relative clause indicated by the square brackets). In Friederici et al.'s [11] study, this was implemented by presenting syllable sequences of the type $A^{n} B^{n}$ (e.g. AABB, AAABBB; assumed hierarchical structures: $\mathrm{A}[\mathrm{AB}] \mathrm{B}, \mathrm{A}[\mathrm{A}[\mathrm{AB}] \mathrm{B}] \mathrm{B})$. The non-recursive grammar, by contrast, consisted of sequences of the type $\mathrm{AB}^{\mathrm{n}}$ (e.g. $\mathrm{AB}$, $\mathrm{ABAB}, \mathrm{ABABAB})$. While, in the former case, the syllable sequences could only be classified correctly as grammatical (or ungrammatical) if the dependency between the different ("hierarchical") levels of As and Bs was recognised, the latter only required participants to learn the local transition between $\mathrm{A}$ and $\mathrm{B}$. An fMRI study revealed that the processing of both grammar types - when grammatical violations were contrasted with grammatical strings - correlated with activation in the left deep frontal operculum, while only embedding grammars engendered additional activation in the lateral convexity of the POp (BA 44). ${ }^{6}$ A similar finding was reported by Makuuchi et al. [54] using natural language (German). In an fMRI study, these authors varied the distance between subject and verb (short, 4 intervening

\footnotetext{
${ }^{6}$ The original design used by Friederici et al. [11], which was adopted from [52], was subject to the criticism that participants may have been able to process the grammar containing embeddings simply by counting the number of occurrences of each type of symbol [10]. This problem was overcome in a follow-up fMRI study [53] which ensured that the corresponding A and B categories (i.e. those at the same structural level) matched according to a particular feature. This experiment also showed increased activation of BA 44 for artificial grammars containing centre-embeddings vs. adjacent dependencies.
}

words vs. long, 8 intervening words) and also whether the sentence including embeddings (i.e. 1 or 2 intervening centre-embedded relative clauses). While the left POp showed a main effect of sentence structure (higher activation for sentences with $v s$. without centre-embeddings), a main effect of distance was observed in the left inferior frontal sulcus (IIFS; higher activation for a long $v s$. short distance between subject and main clause verb). This study also revealed a higher degree of structural coupling between the IPOp and IIFS during the processing of embedded $v s$. nonembedded sentences. Furthermore, diffusion tensor imaging (DTI) showed that the IPOp and IIFS clusters observed in the fMRI analysis were anatomically interconnected in the majority of participants. These results led the authors to conclude that there is a "functional segregation of the core syntactic computation and non-syntactic [verbal working memory], with the former being located in the [left pars opercularis] and the latter being located in the LIFS" ([54], p. $8365)^{7}$

As is apparent from the discussion above, Friederici and colleagues have put forward a rather elaborate proposal regarding syntax-related functional-neuroanatomical dissociations within left inferior frontal regions. Whereas local syntactic computations are assumed to be supported by the DFO, hierarchical syntactic computations are thought to correlate with activation in the POp and general working memory is presumed to be sustained by the IFS. At this point, a clarification appears in order. In the introduction, we discussed the use of sequential information for the establishment of a hierarchical syntactic structure as potentially separate from the processing of flexible sequencing options. This proposed separation is clearly incompatible with Friederici's perspective, since here, local computations which do not involve word order variations or embeddings are also considered to be a potential source of hierarchical syntactic structure. Specifically, we assume that a hierarchy is established at each point where two elements are combined to form a higher-level constituent; for example, when a preposition (P) and a noun (N) (or a noun phrase, NP) are combined to form a prepositional phrase (PP), it is clear that the preposition is the head of the phrase and thus determines its properties. This view is precisely articulated in Chomsky's Minimalist Programme [63], where it is assumed that, if two linguistic elements A and B are combined via the operation Merge, one of the two must "project" in order to determine the properties of the newly created constituent. Thus, a hierarchical structure of the linguistic input does not necessarily require recursion, but rather results from the notion of a hierarchical asymmetry in syntactic structure building (i.e. the idea that the combination of two linguistic elements does not simply serve to form a list; rather, one of

\footnotetext{
7 Note that the distance manipulation employed by [54] is somewhat problematic as a diagnostic of increased working memory costs. A number of behavioural studies in the psycholinguistic literature have provided evidence for so-called "antilocality" effects, i.e. a reduction of processing costs (e.g. in the form of faster reading times) for clause-final verbs with increasing distance from the subject $[55,56]$. These findings are problematic for resource-limited accounts of sentence processing which assume that integrations of distant elements are necessarily more costly than local integrations $[57,58]$ but can be explained by retrieval-based approaches to working memory in sentence processing [59-62]. In view of these observations, the functional interpretation of the IFS activation in [54] is not clear.
} 
the elements is hierachically dominating) in combination with the assumption of binary branching [64]. Hence, embedding or recursion is logically independent of hierarchical linguistic structure: every sentence is hierarchically structured, while only some sentences involve embeddings or recursion. (Diagnostics of hierarchical structure in simple sentences include phenomena such negative polarity items or the binding of anaphora. For an introduction, see [65].) Crucially, even though the precise conception of what it means for a syntactic structure to be hierarchical differs from one theory to another, most major syntactic theories agree that hierarchical structure is conceptually distinct from the notion of embedding [63,66-68].

A possible way of approaching this problem would be to assume that embedding, rather than hierarchical structure, is central to the distinction assumed by Friederici and her colleagues. However, the account would then no longer extend to word order variations in simple sentences, which, like embeddings, lead to increased activation of the IIFG and typically of the POp. If, by contrast, the two phenomena are to be explained by a single generalisation but hierarchical structure is not a suitable candidate, this raises the question of what embeddings and word order variations have in common. We shall return to this question in section 5 below, where we suggest that the key to the separation between word order variations and embeddings on the one hand and the establishment of a hierarchical syntactic structure ("local structure building") on the other may be the use of sequencing cues of differing locality.

\subsection{Possible Solutions II: Syntax as too Narrow}

In contrast to the accounts described in the previous section, which associate (parts of) Broca's region with particular aspects of syntax / specific syntactic operations, other proposals adopt the opposite approach, namely the assumption that syntax is, in fact, too narrow and that the functions in question are actually much broader in nature.

One account of this type is Hagoort's Memory, Unification and Control (MUC) framework [69,70]. Hagoort assumes that complex linguistic representations are constructed via the unification of their constituent parts. Unification is an operation that, in addition to the combination of elements to form more complex expressions, comprises operations of feature checking and specification. In contrast to the operations Merge and Move in Chomskyan syntax, unification is a nonderivational operation; it essentially involves structure sharing between two expression and is therefore a key feature of declarative theories of syntax such as Head-driven Phrase Structure Grammar, HPSG [71]. Crucially for present purposes, unification is not restricted to syntactic representations in Hagoort's view, but is rather thought to apply to all linguistic subdomains (e.g. semantics [72] and phonology [70]); it is also assumed, in principle, to be suited to combining these different information types [69], though the precise mechanisms by means of which this takes place have not been described to date. Thus, the concept of unification is clearly broader than syntax and, in this account, the IIFG is viewed as a region that supports general combinatory processes in language comprehension and production. Hagoort does, however, assume that there may be an additional functional "gradient" across the IIFG which differentiates between the linguistic domains to which unification applies: while the most posterior portion of the IIFG (POp) and adjoining premotor cortex (PMC) are thought to support phonological unification, the central part of the IIFG (PTr and POp) is the locus of syntactic unification, and the most anterior part of the IIFG (POr and PTr) underlies semantic unification [70].

A second "supra-syntactic" perspective on IIFG function during language comprehension focuses specifically on the correlation between POp activation and word order variations. On the basis of the observation that the POp not only shows increased activation for object-before-subject word orders but also for a variety of other linearisation principles, the "linearisation hypothesis" $[45,46]$ proposes that the POp is responsible for the sequencing of sentence constituents. ${ }^{8}$ Crucially, the information types underlying these linearisation principles are not purely syntactic in nature, but rather stem from the syntax-semantics or syntax-pragmatics interface (e.g. the principle higher-ranking thematic role $>$ lowerranking thematic role [45], or the principle animate argument $>$ inanimate argument [47], pronoun $>$ non-pronominal argument [46], definite/specific argument $>$ indefinite/nonspecific argument [49]). Linearisation is thus, like unification, assumed to be a mechanism that can apply to a variety of different linguistic information types.

An even more general perspective on IIFG function is advocated by Thompson-Schill and colleagues [78-80]. These authors have proposed that the 1IFG implements cognitive control mechanisms, specifically the selection of representations from a set of competing alternatives. Selection is a domain-general process that applies to all linguistic information types. Evidence for the selection view stems, for example, from the finding of higher IIFG activation in naming experiments when the number of alternative naming options increases [78], higher IIFG activation for the comprehension of syntactically ambiguous vs. unambiguous sentences (see [80], and the references cited therein), and higher IIFG activation for multiword naming (coordinated noun phrases) under conditions of positional interference [81]. Interestingly, Thothathiri and colleagues' [81] interpretation of their results in terms of "selection for position" provides a potential point of convergence between the selection view and the linearisation hypothesis. Recent findings provided further converging support for the relevance of cognitive control mechanisms to IIFG activations in language by demonstrating a co-localisation of syntactic ambiguity-related IIFG activations and IIFG activation engendered by the Stroop task, i.e. a typical task for tapping cognitive control processes [82]. ${ }^{9}$

\footnotetext{
${ }^{8}$ As such, it appears to mirror the sequencing function of adjacent ventral premotor cortex (vPMC) [73,74]. However, as already pointed out by [45], there is a crucial difference between the sequences that have been shown to activate $\mathrm{vPMC}$ and the linguistic sequencing that leads to activation changes in the POp in that only the latter involve the mapping between sequences and binary hierarchical structures (see [75] for an extensive motivation). Whether the ability to deal with the hierarchical aspect of these structures is unique to language [7] or derives from other cognitive abilities such as the demands of tool use [76] or the combination of motor commands more generally [77] currently remains an open question.

${ }^{9}$ In the Stroop task [83] participants are required to name the colour of the ink in which a colour term is written rather than the colour term itself (e.g. for the word "blue" written in red, the correct response would be "red").
} 
Finally, a classic domain-general explanation for IIFG activation in complex sentences holds that these can be attributed to increased demands on working memory (e.g. [84-88]). For object-initial sentences, for example, it is often assumed that the object must be held in working memory until it can be integrated into its base position behind the subject or associated with the verb (see $[85,88]$ ). Hence, these types of sentences are assumed to tax working memory more strongly than their subject-initial counterparts and are therefore thought to engender increased activation in the IIFG. An explanation along these lines can also account for the observation described above that the IIFG appears to come into play when processing demands become more complex, for example for the processing of word lists $v s$. sentences [28] or for Jabberwocky (pseudoword) sentences $v s$. normal sentences [30] (for discussion, see [85]).

\subsection{Summary}

As is apparent from the discussion in the preceding sections, a host of explanations has been put forward with regard to the neurocognitive bases of syntactic processing in general and, more specifically, with respect to the processing of linguistic sequences. These range from very general (cognitive control, working memory) to very specific (processing of syntactic movement or hierarchical syntactic structures); intermediate-level explanations, which assume linguistic mechanisms that operate over a range of difference information types have also been proposed (unification, linearisation). In the following section, we will evaluate these different accounts against the empirical evidence on the processing of word order.

\section{CHALLENGES: FUNCTIONAL-NEUROANATO- MICAL PATTERNS AND DISSOCIATIONS IN WORD ORDER PROCESSING}

The accounts discussed in the preceding section all attempt to address the apparent absence of a one-to-one mapping between syntax and the IIFG. To this end, some narrowed the syntax-related function of this cortical region, while others broadened it. In this section, we will discuss the empirical challenges for these accounts that are posed by findings on the processing of word order variations.

\subsection{Challenge I: Fine Grained Word Order-Related Activation Changes in the Left POp}

Firstly, the finding that left POp activation is modulated by a range of linguistic linearisation principles (for recent overviews, see $[6,49]$ ) challenges both specific and domaingeneral accounts of Broca's area function. For a representative illustration, consider the following example sentences from Grewe et al., [47].

\section{(2) Example stimuli from [47]}

a. Dann wurde der Mantel dem Arzt gestohlen. then was [the coat $]_{\mathrm{NOM}}[\text { the doctor }]_{\mathrm{DAT}}$ stolen 'Then the coat was stolen from the doctor.'

This conflict between the two information sources leads to interference, as is measurable, for example, in slower reaction times in comparison to nonconflicting stimuli in which the colour term matches the colour of the ink in which it is written. b. Dann wurde dem Arzt der Mantel gestohlen. then was [the doctor $]_{\mathrm{DAT}}[\text { the coat }]_{\mathrm{NOM}}$ stolen 'Then the coat was stolen from the doctor.'

In an fMRI study, Grewe and colleagues observed increased left POp activation for sentences such as (2a) in comparison to ( $2 b)$, i.e. increased activation for subject-initial sentences in comparison to their object-initial counterparts. They attributed this pattern of results to the violation of the linearisation principle animate $>$ inanimate in (2a) vs. (2b). (Crucially, note that all sentences were grammatical. "Violation" in the sense used here is thus to be understood as the violation of a preference rather than of an inviolable syntactic rule.) A control comparison between similar sentences with two animate arguments (e.g. Dann wurde der Polizist dem Arzt vorgestellt / Dann wurde dem Polizisten der Arzt vorgestellt, "Then, the policeman was introduced to the doctor") did not reveal any inferior frontal activation differences. ${ }^{10}$ As we will outline in more detail in the following, this result is not compatible with any account which attributes increased activation of Broca's region, and specifically of the POp, to the reconstruction of a permuted word order to a basic, underlying word order.

Before turning to the individual accounts in question, however, it is important to note that the findings by Grewe et al., [47] are by no means exceptional: other studies conducted on German and employing a comparable methodology revealed similar results for a range of other information types that defy a straightforward explanation in terms of movement / reconstruction to a basic underlying word order that allows for semantic interpretation (thematic roles [45], pronominality [46], definiteness/specificity [49]). Likewise, Chen et al., [89] found that the well-known result of increased IIFG activation for object vs. subject relative clauses in English can be modulated by animacy: there is no longer a measurable activation difference between the two relative clause types in this region when the head noun of the relative clause is inanimate and the relative clause subject is animate (e.g. The wood that the man chopped heated the cabin). This again attests to the fact that structural factors do not provide a complete explanation for the correlation between the IIFG and word order variations. We shall return to the significance of the particular information types (animacy, definiteness/specificity, pronominality, semantic roles) involved in modulating these supra-structural activation differences in the IIFG below. At this point, however, we refer to these data primarily in order to make clear that the challenges for several accounts which we will outline below with reference to the Grewe et al., [47] data are not based upon a single result, but rather on a range of highly consistent findings.

\footnotetext{
${ }^{10}$ Note that the absence of an activation difference between the two orders for sentences containing only animate arguments in predicted by the linearisation hypothesis. Under these circumstances, the linearisation principle "higher thematic role > lower thematic role" calls for the dative (Recipient) to precede the nominative (Theme), while case-based linearisation calls for the opposite order (nominative-before-dative). As shown in [45], when these principles are in conflict and no third principle is applicable in order to "arbitrate" between the two, no activation differences are observable in the POp. When there is an additional animacy difference, however, as in (2), the principle "animate > inanimate" can fulfil this arbitrating function [47].
} 
The results by Grewe et al., [47] and the related findings described above are not compatible with an explanation in terms of syntactic movement (e.g. [15,16,90]): (in)animacy is not assumed to be a trigger for movement in any existing syntactic account of word order in German and other potential structural differences between (2a) and (2b) also differ between the sentences in the control comparison and therefore cannot be responsible for the selective activation difference between the sentences in (2). Similar considerations hold with respect to Friederici's account. While here, it is not entirely clear whether a movement-based perspective on word order variations is assumed or not, there are several indications that Friederici's notion of "hierarchical syntax" in word order variations is to be understood in terms of movement. Consider, for example, the following passage from Grodzinsky and Friederici [90]:

The reconstruction of the interpretation of a sentence becomes increasing difficult for non-canonical sentences (e.g., object-first sentences) in which the order of the arguments (word order) does not enable direct mapping to the underlying syntactic structure. In such cases, hierarchical syntactic structures must be constructed from sequential input. These computations are supported by Broca's areas (BA 44/45). Activation in this area is determined by the degree of deviance from canonicity of a sentence, defined as the number of operations necessary to reconstruct the basic structure of the sentence. Such deviations mostly amount to 'movement' [...]." ([90], p.244)

This statement makes clear that Friederici assumes a reconstruction to a basic word order which, as is noted elsewhere in [90], is required for the assignment of semantic roles ("who is doing what to whom") in her view. ${ }^{11}$ Thus, the results by Grewe et al., [47] pose a similar problem for this approach as already described above with regard to a purely movement-based account.

Perhaps somewhat surprisingly, working memory (WM) accounts encounter similar problems when faced with data of this kind. Recall from section 3.2 that WM-based explanations of increased IIFG activation for word order variations typically assume that a permuted object must be held in memory until it can be reconstructed to its base position or integrated with the verb. How could this apply to the sentences in (2)? As already described with regard to a movement-based account above, the control comparison with sentences containing only animate arguments rules out structural differences as the source of the activation difference. Hence, one would need to assume that the basic word order of sentences with an inanimate nominative and an animate dative argument in German is object-beforesubject, while this is not the case for sentences with two animate arguments (in fact, basic word order would need to

\footnotetext{
${ }^{11}$ Note that the full range of neuroimaging findings from German reveals a further problem in this regard, since increased IIFG activation appears to be restricted to a particular type of movement. While clause-medial word order variations in German consistently engender POp activation (see main text), wh-questions [88] and relative clauses [87] only engender increased POp activation under specific circumstances (depending, for example, on the point of disambiguation). Thus movement per se appears to be too broad a cover term. (For a somewhat similar proposal, see [35]. However, the specific assumptions put forward by these authors are problematic when applied to the German data; see [91] for discussion).
}

be indeterminate in this case in order for the absence of an activation difference between the control sentences to be derivable). Furthermore, even if an object-initial base order were assumed for sentences such as (2a), the need to reconstruct to this word order would not yet be apparent at the position of the initial inanimate nominative, since an intransitive continuation is still possible at this point (e.g. Dann wurde der Hut gestohlen, "Then the hat was stolen."). Thus, the manipulation in (2) is not at all comparable to the comparison between object-before-subject and subjectbefore-object orders on which the assumptions of WMaccounts of the IIFG activation for word order variations were based. The findings on animacy by Grewe et al., [47] thus do not lend themselves to a WM-based explanation; the same holds for Chen et al.'s [89] results on English relative clauses, since object relatives always have the same syntactic structure independently of the animacy of the arguments, and for the other findings on German word order variations discussed above $[45,46,49]{ }^{12}$

How, then, do the remaining accounts that were discussed in section 3 fare in light of these data? With regard to Hagoort's account, it is not entirely clear how unification could account for the word order findings, since different word orders don't differ in terms of the unification demands that they impose. Building upon a computational model of syntactic processing [94], Hagoort [69, 70] assumes lexicalist syntactic templates, i.e. a transitive sentence comprises a template that is headed by a lexical verb with slots for the two arguments, which are filled via unification. There is no movement and different argument orders are derived via linear precedence rules (this is at least the case in Vosse and Kempen's original model; Hagoort has not specified how his framework deals with word order variations to date). Thus, sentences (2a) and (2b) differ with regard to the application of these precedence rules rather than in terms of unification. In order to account for the word order findings, the MUC framework would thus need to be supplemented with a component for the computation of linear precedence much like what is assumed by the linearisation hypothesis. Furthermore, the neuroanatomical localisation of the precedence component would need to overlap with the loci for phonological and syntactic unification. Thus, while the word order

\footnotetext{
${ }^{12}$ Possibly, the data could be approached via a WM-account that assumes content-addressable retrieval mechanisms (i.e. working memory as the activated portion of long-term memory) rather than a separate WM buffer [59-61,92,93]. In accounts of this type, maintenance of information in WM and decay of information during maintenance is not crucial, since no separate (capacity-limited) WM system is assumed (see also Footnote 6). Rather, processing complexity is thought to increase when elements must be retrieved from memory and the retrieval cues employed to this end match several possible candidate elements, thus creating "retrieval interference". From this perspective, one might propose that the initial argument is retrieved when the second argument is encountered and that this retrieval becomes more difficult in certain linearisation scenarios. However, an explanation along these lines is not straightforward, since increased activation of the POp arises exactly when similarity-based interference should be low (i.e. when there is an animacy difference between the arguments in example 2 as opposed to when there is not; see also Footnote 7). Furthermore, even if an account based on retrieval interference could be formulated successfully with regard to the data under discussion here, this would essentially bring us to a proposal that is conceptually very similar to the cognitive control approach put forward by Thompson-Schill and colleagues (see section 3.2). It is also important to note that all existing WM-based accounts of IIFG activation in sentence comprehension have based their assumptions on maintenance rather than retrieval mechanisms.
} 
data could potentially be derived in Hagoort's framework via the addition of further components, the elegance of ascribing IIFG activations in language to the unification of various linguistic information types would be lost. ${ }^{13}$

Turning now to the second "intermediate level" account, the linearisation hypothesis, it is perhaps not surprising that this approach is well suited to deriving the data discussed in this section since the focus lay on word order processing. The assumption of a range of linearisation principles which interact to determine the sequence of elements within a sentence accounts not only for increased POp activation with object-before-subject orders, but also for the other word order-related activation changes in this region (e.g. due to animacy, definiteness/specificity, pronominality and semantic roles; see above). However, a clear disadvantage of the linearisation hypothesis is that it is rather narrow in scope: since, in its original formulation, it focuses only on linearisation / sequencing, it is not suited to deriving findings on IIFG activation that stem from word order-independent manipulations.

Finally, consider the cognitive control account. Assuming that there are multiple competing linearisation principles (as posited by the linearisation hypothesis and a range of theoretical accounts on word order in German, e.g. $[95,96])$, the notion that selection between competing alternatives engenders IIFG activation appears potentially compatible with the word order data discussed in this section. However, what is not entirely clear is why the violation of a linearisation rule should lead to increased POp activation (e.g. in $2 \mathrm{a} v s .2 \mathrm{~b}$ ), since selection demands are equivalent in both sentences (i.e. the same linearisation rules are applicable in each case). In this regard, one could perhaps posit that demands on cognitive control increase when the sentence currently being processed requires a linearisation rule to be overridden, i.e. calls for the inhibition of the interfering rule. Overall, the cognitive control account thus fares quite well with regard to the word order data. It does, however, require additional assumptions about the nature and number of linearisation principles among which the system must select. ${ }^{14}$

\subsection{Challenge II: A Dissociation between Different Sequencing Demands within the IIFG}

The preceding section showed that fine-grained word order-related activation changes in the POp pose a challenge for a number of the accounts that have been put forward with

\footnotetext{
13 Interestingly, Hagoort's notion of unification in principle also appears suited to deriving Friederici and colleagues' findings on embedding $[11,53,54]$ : since sentences are represented as single templates in Hagoort's account, the embedding of one sentence within another would impose additional demands on unification in comparison to a simple linear extension within a single template.

${ }^{14}$ In this context, an interesting potential dissociation emerges between cognitive control accounts based on selection and those assuming similaritybased interference in retrieval (see Footnote 9). Selection predicts increased activation with an increasing number of applicable rules (i.e. with increasing differences between the arguments, e.g. in terms of animacy, definiteness etc.) By contrast, retrieval interference should make exactly the opposite prediction, since increasing differences between the arguments serve to reduce interference. If both mechanisms indeed apply during language processing, they could thus potentially be distinguished in functionalneuroanatomical terms.
}

regard to functional role of the IIFG in language processing. In this section, we will now describe a second challenge, namely the observation that different sequencing demands appear to engender activation in different subparts of the IIFG. Furthermore, we will discuss how an extension of the linearisation hypothesis can derive these observations.

While the results discussed in the previous section showed a very robust correlation between the processing of word order variations and the POp, there are some indications that word order-related activation changes in simple sentences may also show activation maxima in the PTr ([97] for German, [35] for Hebrew, [25] for Japanese). Notably, all of these studies (see 3-5 for examples) differed from those described in section 4.2 in that they involved object fronting to the clause-initial position (all three studies contrasted object-before-subject with subject-before-object orders) rather than argument order permutations within a clause-medial region (the German "middlefield"). This observation (see also Fig. (1) for an illustration) led Bornkessel-Schlesewsky and Schlesewsky [91] to speculate that the different activation maxima may "be somehow related to the positioning of the object within the overall clause" [91, p. 152], i.e. to the difference between word order permutations targeting a clause-medial vs. the clauseinitial position.

\section{(3) Example stimuli from [97]}

a. Object-verb-subject

Den begabten Sänger entdeckte während der

Weihnachtsfeier

[the gifted singer $]_{\mathrm{ACC}}$ discovered during the

christmas.party

der talentierte Gitarrist.

[the talented guitar.player $]_{\mathrm{NOM}}$

'The talented guitar player discovered the gifted singer during the Christmas party.'

b. Subject-verb-object (control)

Der begabte Sänger entdeckte während der

Weihnachtsfeier

[the gifted singer $]_{\mathrm{NOM}}$ discovered during the

christmas.party

den talentierte Gitarristen.

[the talented guitar.player $]_{\mathrm{ACC}}$

'The gifted singer discovered the talented guitar player during the Christmas party.'

(4) Example stimuli from [35]

a. Object-subject-verb

'et ha-sefer ha-'adom John natan la-professor me-oxford [ACC the-book the -red] John gave [to-the-professor from-Oxford]

"John gave the red book to the professor from Oxford."

b. Subject-verb-object (control)

John natan 'et ha-sefer ha-'adom la-professor me-oxford John gave [ACC the-book the -red] [to-the-professor from-Oxford]

"John gave the red book to the professor from Oxford."

(5) Example stimuli from [25]. Note that this study employed a sentence-picture matching task; the geometrical shapes in the sentences thus refer to stick figures with heads depicted as the respective shapes. 
a. Object-subject-verb

$\square$-o O-ga oshiteru

$\square$-ACC O-NOM pushes

"O pushes $\square$ "

b. Subject-object-verb (control)

O-ga $\square$-o oshiteru

O-NOM $\square$-ACC pushes

"O pushes $\square$ "

In order to examine this apparent distinction between the clause-initial position and the clause-medial region more closely, Bornkessel-Schlesewsky et al., [6] directly contrasted clause-initial and clause-medial word order permutations in German in a within-participants design. The critical sentence conditions used in this study are illustrated in example (6).

(6) Example stimuli from [6]. Only the object-initial conditions are shown; in the subject-initial controls, the position of subject and object was interchanged.

a. Object-before-subject order - clause-medial

Peter behauptet, dass den Arzt der Lehrer verfolgt hat.

Peter claims that $[\text { the doctor }]_{\mathrm{ACC}}[\text { the teacher }]_{\mathrm{NOM}}$ pursued has

'Peter claims that the doctor pursued the teacher.'

b. Object-before-subject order - clause-initial

Peter behauptet, den Arzt hat der Lehrer verfolgt.

Peter claims $[\text { the doctor }]_{\mathrm{ACC}}$ has $[\text { the teacher }]_{\mathrm{NOM}}$

pursued

'Peter claims the doctor pursued the teacher.'

Bornkessel-Schlesewsky et al., [6] indeed observed activation differences within different subregions of the IIFG for the different sentence types employed (see Fig. (1) for a visualisation of the activation maxima): whereas posterior portions of the IIFG (primarily the POp) showed a main effect of argument order (higher activation for object-initial $v s$. subject-initial word orders), more anterior regions of the IIFG (including the PTr) showed effects of both argument order and sentence type (higher activation for object-initial vs. subject-initial word orders and for sentences with an argument in the clause-initial position of the embedded clause vs. sentences in which the embedded clause was introduced by a complementiser). Thus, rather than showing a selective response to object-initial orders targeting the clause-initial region, anterior portions of the IIFG generally responded to the positioning of an argument in the clauseinitial position (in addition to the relative positioning of subject and object). Bornkessel-Schlesewsky et al., [6] interpreted this finding with reference to the special information structural status of the clause-initial position: by default, an argument residing in this position is interpreted as the sentence topic, i.e. the entity which the sentence is about (see, for example, [98] and the references cited therein). In the presence of a discourse context, this sentence topic might also be expected to correspond to the discourse topic, i.e. to the entity under discussion in the discourse. It is also typically the subject of the sentence rather than the object [99]. Bornkessel-Schlesewsky and colleagues thus argued for a sequencing gradient within the IIFG, with more anterior regions engaging in "aboutness-based sequencing" (i.e. determining which argument is to reside in the position which correlates with aboutness-based topicality) and more posterior regions engaging in "prominence-based sequencing". Prominence-based sequencing is based on the inherent properties of the arguments and the prominence scales in (7) and essentially corresponds to the linearisation principles described in the discussion of the linearisation hypothesis in section 3.2. Notably, in addition to influencing argument order in a range of different languages [100], these prominence scales are well known in language typology because they influence morphosyntactic properties in many languages of the world (see, for example, [101,102]). In some languages, for example, only direct objects that are high in prominence (e.g. inanimate: Spanish; non-specific: Turkish; inanimate and non-specific: Hindi) are marked via case or a preposition ("differential object marking", DOM, [103,104]). This phenomenon is often explained via the prototypical association between subjects (which often express the actor of an event) and high prominence (e.g. animacy) and objects (which often express the undergoer of an event) and low prominence (e.g. inanimacy) (e.g. [101,104-106]). (For an in-depth discussion of prominence information in the context of language processing, see [107]).

(7) Prominence scales

a. +animate $>$-animate

b. +definite/+specific $>$-definite/-specific

c. + first $/$ second person $>$-first/second person.

Thus, sequencing options based on prominence features depend on the properties of the arguments themselves and the relation between them, sequencing options based on aboutness depend on what the sentence is construed to be about and are thus not closely linked to individual argument properties. The findings by Bornkessel-Schlesesky et al., [6] thus suggest that different types of sequencing may dissociable from the perspective of functional neuroanatomy.

These results therefore present an additional challenge to existing accounts of IIFG function in language processing. In addition to the modulations of IIFG (POp) activation in response to what appears to be "pure sequencing" (i.e. mechanisms that cannot be reduced to general cognitive concepts such as working memory or to specific syntactic operations such as movement; see the preceding section), there appear to be differential activation foci in inferior frontal cortex depending on the type of sequencing under examination (i.e. the nature of the information on which sequencing decisions are based). This observation is not predicted by any of the accounts discussed in the preceding sections. In the following and final section of this paper, we will therefore describe a new approach which is not only suited to deriving these findings but also has broader consequences for the cognitive and neural bases of linguistic sequencing.

\section{LINGUISTIC SEQUENCING AND A HIERARCHY OF COGNITIVE CONTROL PROCESSES IN PRE- FRONTAL CORTEX}

In interpreting their findings, Bornkessel-Schlesewsky et al., [6] draw parallels between the gradient of linguistic sequence processing that they observed within the IIFG (see above) and a hierarchy of cognitive control processes described by Koechlin and colleagues [1,5,108]; the examples 
are due to [1], the interpretation of the different control cues in terms of levels of locality is our own:

(a) Stimulus-driven control draws upon the most basic type of control cue and is thought to be implemented by premotor cortex (i.e. the most posterior portion of the prefrontal control gradient). It consists of simple stimulus-response mappings, such as the tendency to answer the telephone when it rings. This type of control cue is thus closely associated with the critical stimulus itself and is therefore relatively "local".

(b) Contextual control hierarchically dominates stimulusdriven control and implies that stimulus-response mappings can be determined or overridden by the current episode within which an individual finds him-/herself. For example, when visiting a friend's house, we may be less likely to pick up the phone when it rings as opposed to when we are at home. Neuroanatomically, contextual control correlates with more anterior regions of frontal cortex than stimulus-driven control (e.g. with posterior portions of the IIFG such as the POp). This type of control cue is less local than stimulus-driven control, since it requires assessment of the stimulus in relation to the current context in which it occurs.

(c) Episodic control involves the possibility of overriding contextual control with reference to past events. For example, if the friend who I am currently visiting asks me to answer the phone because he/she is working but expecting an important call, I will do so in spite of the contextual control cue "at a friend's house". This type of control, which is associated with even more anterior portions of frontal cortex (typically BA 46, [1,5]), is again less local than contextual control because it involves relating the current stimulus (and context, possibly) to a distal event that took place at some point in the past.

(d) Branching control is the most abstract type of control within the hierarchy and correlates with the most anterior portions of prefrontal cortex (frontopolar cortex corresponding to lateral BA 10). It permits switches between different types of control scenarios. For example, assuming (as in c above) that my friend asked me to answer his/her phone while staying at his/her house, he/she could temporarily undo this request by stating that he/she would like to take the next call $\mathrm{him} /$ herself because it is going to be particularly important. I would then refrain from answering the phone the next time it rings (effectively disenabling the currently active episodic control cue), but would return to "answering mode" with the following phone call (thereby reenabling the episodic control cue).

Bornkessel-Schlesewsky et al., [6] argue that their finding of a sequencing gradient along the anterior-posterior dimension of the IIFG precisely correlates with this hierarchy of cognitive control (see Fig. (2), for an illustration). They assume that prominence-based sequencing can be described as requiring contextual control, because the prominence properties of the current stimulus element must be assessed in relation to the (sentence-internal) context in which they occur, i.e. with respect to the prominence status of the coarguments. Aboutness-based sequencing, by contrast, is more closely associated with episodic control, because it requires a link to a distal (sentence-external) event: the broader discourse and the referents under discussion in it or the speaker's intention with regard to what the sentence is about. Accordingly, aboutness-based sequencing correlates with activation in more anterior portions of the IIFG than prominence-based sequencing. This proposal thus shows how the linearisation hypothesis can be extended to encompass different types of sequencing cues and how it can be linked to broader cognitive processing mechanisms. It of course shows clear parallels to Thompson-Schill and colleagues' cognitive control approach to IIFG function in language (e.g. [78,80,82]), but makes the additional claim that the abstractness (or locality) of the currently relevant control cue may play a crucial role in determining localisation within frontal cortex.

Interestingly, the proposal advanced in BornkesselSchlesewsky et al., [6] can be extended even further. Recall from section 3.1 that the processes of local phrase structure building which comprise "local syntax" in Friederici's account can be described (in processing terms) as the analysis of a sequence A B into an overarching constituent $\mathrm{C}$, with the characteristics of $\mathrm{C}$ determined either by $\mathrm{A}$ or $\mathrm{B}$ depending on their lexical properties (in terms of Chomsky's Merge, either A or B "projects"). This type of "stimulusdriven projection" appears highly compatible with the notion of stimulus-driven control: whether an element projects or not is essentially a stimulus-inherent property and can thus be described in terms of an (abstract) stimulus-response mapping (the response being a linguistic analysis rather than a behavioural reaction in this case). This assumption fits perfectly with Friederici and colleagues' empirical observations, which suggest that local structure building of this type correlates with activation in the DFO, a region that is cytoarchitectonically comparable to premotor cortex rather than to the lateral surface of the IFG $[11,42,43]$. From this perspective, what we termed the use of sequence information for the establishment of a hierarchical syntactic structure in the introduction amounts to the use of linguistic sequence information under the most local conditions of cognitive control (stimulus-driven control) and thereby correlates with activation in the most posterior portions of prefrontal cortex. ${ }^{15}$ By contrast, word order variations in simple sentences (prominence-based sequencing) call for a relational

\footnotetext{
15 It remains to be seen whether this assumption is, in fact, crosslinguistically valid. While the assumption that languages such as German or English lexically encode word category and that this lexical information directly and unambiguously determines whether an element is potentially a projecting head or not, other languages display a considerable degree of fluidity in this regard ("transcategoriality"). A case in point is Mandarin Chinese, in which a large number of lexemes can potentially function as different word categories (e.g. noun or verb) depending on the sentence context in which they occur [109]. Possibly, the use of sequence information for the establishment of a hierarchical syntactic structure therefore involves processes of contextual control rather than stimulus-driven control in languages of this type and should thereby be expected to correlate with activation in the POp rather than in the DFO / PMC. An initial indication that this might indeed be the case stems from an early imaging study on Chinese [110] which reported activation in BA 44 (amongst other inferior frontal regions) for a category sequencing violation (verb-adverb order). However, since this activation was revealed by a contrast between the sequencing violation and a font change detection condition (i.e. a relatively low level control), this result cannot be considered conclusive with regard to the question under consideration.
} 
comparison between the properties of the current stimulus and the (sentence-internal) context in which it is encountered and thereby require a less local form of control, namely contextual control. They thus correlate with activation in a slightly more anterior region of frontal cortex, typically the POp.

How does embedding, which, according to Friederici and colleagues' studies (e.g. [11,53,54]) shows similar neuroanatomical correlates to word order variations, fit into this picture? Clearly, embedding requires a less local form of control than local structure building since it is not simply dependent on the inherent properties of the current stimulus. Rather, it resembles prominence-based sequencing in that it requires a comparison between the properties of the embedded clause and that of the main clause. This relational comparison is required, on the one hand, because only certain types of phrases can be embedded recursively (sentences and noun phrases, but not, for example, prepositional phrases). On the other hand, embedding at the sentence level also involves sequencing, since many languages allow embedded clauses (complement clauses, relative clauses) to be "extraposed" to a sentence-final position, i.e. to a position following the main clause. Whether an embedded clause is extraposed or not depends, for example, on its "heaviness", namely on the relative length of the embedded clause in comparison to the main clause (e.g. [111]). Taken together, embedding shows very similar properties to prominencebased sequencing in that both require relational comparisons between the properties of multiple elements within a sentence. As discussed above, this process can be described in terms of contextual control. Indeed, an account along these lines receives converging support from the observation that the IIFG (BA 44/45) shows increased activation for centreembedded $v s$. left-branching sentences involving embedding in Japanese [112], an early functional imaging result that was originally used to argue for the syntactic specialisation of the IIFG. More recent findings using a repetition suppression design in English also indicate that the posterior IIFG (BA 44) adapts to the positioning of an embedded clause relative to the main clause [41].

Interestingly, extraposition of embedded clauses may even occur in consistently head-final languages such as Turkish, as illustrated by example (8).

$$
\begin{aligned}
& \text { Č1k-1p kendi-ler-in-i savun-sun-lar bu haksılik-lar-1 } \\
& \text { yap-an-lar } \\
& \text { come-out-ger self-pl-poss-acc defend-opt-3pl this } \\
& \text { injustice-pl-acc do-SP-pl } \\
& \text { "Let the ones who committed those injustices come } \\
& \text { out and defend themselves." } \\
& \text { (from [11], p. 365). }
\end{aligned}
$$

According to [113], the postverbal positioning of the subordinate clause "the ones who committed those injustices" follows from the information structure of the sentence, which was uttered at a point in a conversation when the injustices committed by a particular political party had been under discussion. Thus, the information expressed postverbally was contextually recoverable and could thus be backgrounded. Under these circumstances, the sequencing requirements tied to an embedded clause appear closer to those described with regard to aboutness-based sequencing above and may therefore require episodic rather than contextual control. This makes the prediction that, when the positioning of an embedded clause has information structural implications, we may see an activation shift to portions of the IIFG that are more anterior than the POp.

Crucially, the explanation advanced here derives the activation differences between sentences with and without embedding [54] without requiring any reference to the notion of recursion. Thus, an explanation of these findings does not necessarily presuppose that recursion is the one unique characteristic of human language [7] and that, as such, it is associated with a specialised neural substrate that differentiates humans from non-human primates. ${ }^{16}$ The control-based account also explains why embedding and (prominencebased) word order variations in simple sentences cluster together in neuroanatomical terms - as noted above, Friederici's explanation in terms of hierarchical syntax is problematic in this regard, since local structure building also establishes a hierarchical syntactic structure. Moreover, our account has advantages in terms of parsimony, since it draws upon mechanisms which also apply to non-linguistic information processing and shows how these can be applied to the processing of and extraction of information from linguistic sequences.

A currently open question is whether the most abstract type of control cue assumed by Koechlin and colleagues, branching control, also has a linguistic correlate. One might speculate that the need to choose between appropriate pragmatic scenarios could be a potential candidate in this regard. In other words, there may be situations in which the correct episodic control cue - as required, for example, in aboutness-based sequencing - changes depending on the addressee of one's utterance. Some word order variations are more appropriate in spoken as opposed to written language (e.g., according to [113], the postverbal positioning of sentence constituents in Turkish) and, even in spoken language, one might be more likely to use these types of constructions when speaking with one's peers as opposed to, say, a teacher or a superior. A context in which one is likely to encounter both types of addressees such as an office Christmas party, for example, would then require flexible switching from one contextual control scenario to another depending on one's current interlocutor. Similarly, the choice of appropriate language in a bilingual setting might be another candidate scenario requiring branching control. However, as noted above, these proposals only constitute first speculations and clearly require further examination in future research.

Finally, while the discussion in this paper has focused on the syntactic aspects of sequencing (i.e. determining linear precedence and hierarchical dominance relations on the basis of different sequencing cues), we believe that the control cues in question can be extended to the semantic domain in a

\footnotetext{
${ }^{16}$ Indeed, the recursion assumption is highly controversial for a number of reasons. Firstly, it has been called into question from a theoretical linguistic perspective [e.g. 8]. Secondly, empirical studies suggest that the behavioural distinction between humans and non-human primates in artificial grammar learning on which Hauser and colleagues' proposal is based is not as clearcut as originally claimed [10]. Thirdly, the recent observation that songbirds can apparently process recursion [114] also indicates that it may not be a uniquely human ability.
} 


\section{Neuroimaging findings on word order permutations in simple sentences}
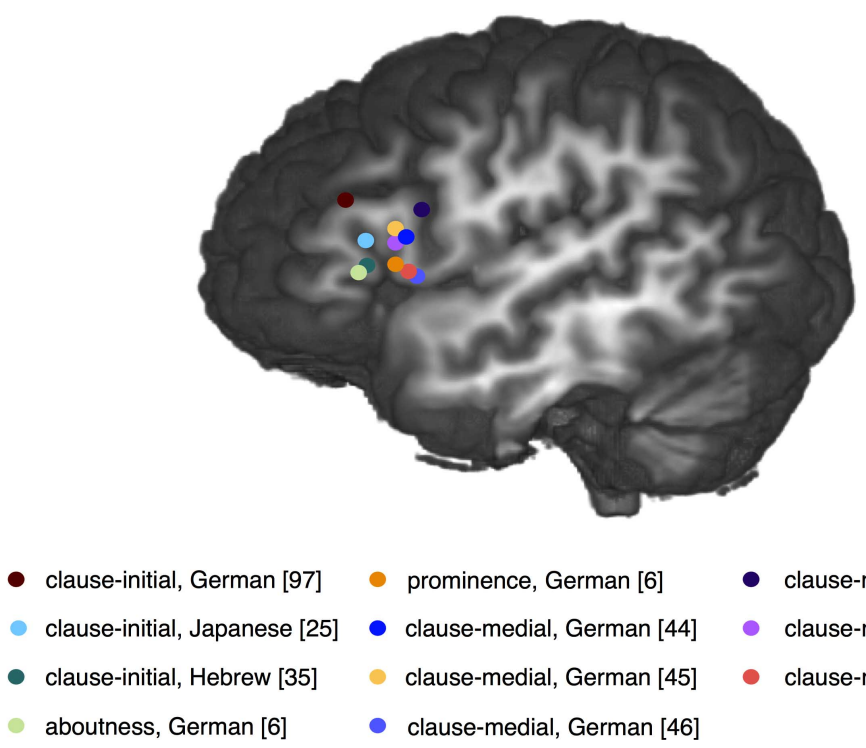

Fig. (1). Illustration of the activation maxima of ten fMRI experiments on word order permutations in simple sentences (i.e. no studies involving relative clauses, wh-questions etc.). The figure shows that the studies in which the order permutation targeted the clause-initial position engendered more anterior (PTr) activation maxima, whereas clause-medial order permutations reliably correlate with more posterior (POp) activation maxima. Further converging support for this dissociation stems from the dissociation between "aboutness-based" and "prominence-based" sequencing in [6].

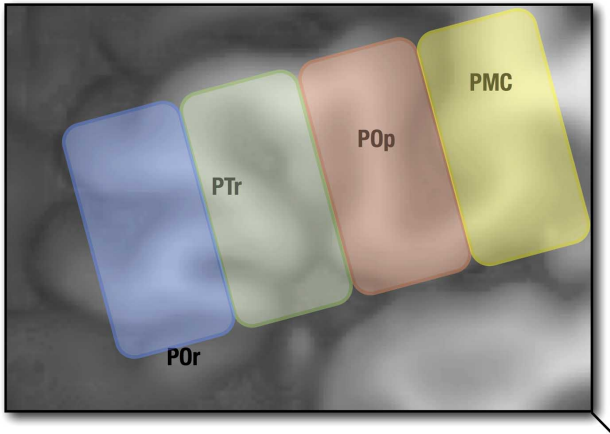

local (phrasal) sequencing (head-complement) stimulus-based control (head projects; determines complement )

\section{prominence-based sequencing}

contextual control (relational comparison of current element to current sentence context; inherent features)

$\mathrm{PMC}=$ Premotor cortex

POp $=$ Pars opercularis

$\mathrm{PTr}=$ Pars triangularis

POr $=$ Pars orbitalis

\section{aboutness-based sequencing}

episodic control (relational comparison of current element to discourse

context / intention of speaker; external (past) features)

\section{pragmatic appropriateness (sequencing?)}

branching control (dynamic switching between different control situations)

Fig. (2). Schematic illustration of how the hierarchy of cognitive control processes assumed by Koechlin and colleagues [1,5] can be applied to different aspects of linguistic sequencing.

relatively straightforward manner. A first proposal as to how this might be accomplished is summarised in (9).

(9) Possible semantic correlates of the control types assumed here

-stimulus-driven control: head-complement / functor-argument relations

-contextual control: co-argument relations / relations between different clauses (embedding)

-episodic control: information structure

-branching control: pragmatic appropriateness.

The proposal in (9) shows how sequence processing under differing types of cognitive control could be used to extract various aspects of semantic information. For example, the head-complement relations established via stimulus- 
driven control (the head being the element which projects, see above) translate into functor-argument structures in semantic terms $[115,116]$. The relative prominence of the coarguments in a sentence, by contrast, not only determines linear order but also semantic aspects of co-argument relations (e.g. role prototypicality, see [107]). Finally, the semantic/pragmatic implications of information structure and pragmatic appropriateness, which we assume to correlate with episodic and branching control, respectively, should be readily apparent. In this way, the present proposal can be extended beyond the domain of sequencing per se to the extraction of information from a linguistic sequence.

\section{CONCLUSIONS}

Based on a review of the functional neuroimaging literature on sequence processing and the prefrontal cortex, we have proposed that the data provide evidence for a gradient of sequencing operations which is organised along the posterior-anterior dimension and which is associated with successively less local cognitive control cues. This account is highly parsimonious, since it draws upon an existing extralinguistic proposal regarding a hierarchy of cognitive control processes in prefrontal cortex ([1], for a review) and shows how these can be used to derive functional-neuroanatomical distinctions in frontal cortex among different aspects of syntactic processing. We have also argued that it can potentially be extended beyond the $\pi$ processing of sequences to the extraction of semantic and pragmatic relations from the sequence information. It could therefore constitute the foundation for a new neurocognitive framework for sentence processing.

\section{CONFLICT OF INTEREST}

None declared.

\section{ACKNOWLEDGEMENT}

None declared.

\section{REFERENCES}

[1] Koechlin E, Summerfield C. An information theoretical approach to prefrontal executive function. Trends Cogn Sci 2007; 11: 22935 .

[2] Kayne RS. The Antisymmetry of Syntax. Cambridge, MA: MIT Press 1994.

[3] Stabler E. Perspectives on sentence processing. In: Clifton C Jr, Frazier L, Rayner K, Eds. Hillsdale: Erlbaum 1994; pp. 303-36.

[4] Steele S. Universals of human language. In: Greenberg JH, Ed., Vol. 4: Syntax. Stanford, CA: Stanford University Press, 1978; 585-623.

[5] Koechlin E, Ody C, Kouneiher F. The architecture of cognitive control in the human prefrontal cortex. Science 2003; 302: 1181-5.

[6] Bornkessel-Schlesewsky I, Grewe T, Schlesewsky M. Prominence $v s$. aboutness in sequencing: a functional distinction within the left inferior frontal gyrus. Brain Lang 2012; 120: 96-107.

[7] Hauser MD, Chomsky N, Fitch WT. The faculty of language: what it is, who has it, and how did it evolve? Science 2002; 298: 156979.

[8] Pinker S, Jackendoff R. The faculty of language: what's special about it? Cognition 2005; 95: 201-36.

[9] Corballis MC. Recursion, language and starlings. Cogn Sci 2007; 31: 697-704.
[10] Perruchet P, Rey A. Does the mastery of center-embedded linguistic structures distinguish humans from nonhuman primates. Psychon Bul Rev 2005; 12: 307-13.

[11] Friederici AD, Bahlmann J, Heim S, Schubotz RI, Anwander A. The brain differentiates human and non-human grammars: Functional localization and structural connectivity. Proc Natl Acad Sci USA 2006; 103: 2458-63.

[12] Caramazza A, Zurif E. Dissociation of algorithmic and heuristic processes in language comprehension: evidence from aphasia. Brain Lang 1976; 3: 572-82.

[13] Novick JM, Kan I, Trueswell JC, Thompson-Schill SL. A case for conflict across multiple domains: memory and language impairments following damage to ventrolateral prefrontal cortex. Cogn Neuropsychol 2009; 26: 527-67.

[14] Dronkers NF, Wilkins DP, Van Valin RD Jr, Redfern BB, Jaeger JJ. Lesion analysis of the brain areas involved in language comprehension. Cognition 2004; 92: 145-77.

[15] Grodzinsky Y. The neurology of syntax: language use without Broca's area. Behav Brain Sci 2000; 23: 1-71.

[16] Grodzinsky Y, Santi A. The battle for Broca's region. Trends Cogn Sci $2008 ; 12: 474-80$.

[17] Geschwind N. The organization of language and the brain. Science 1970; 170: 940-4.

[18] Just MA, Carpenter PA, Keller TA, Eddy WF, Thulborn KR. Brain activation modulated by sentence comprehension. Science 1996; 274: $114-6$

[19] MacDonald MC, Christiansen MH. Reassessing working memory: comment on Just and Carpenter (1992) and Waters and Caplan (1996). Psychol Rev 2002; 109: 35-54.

[20] Stromswold K, Caplan D, Alpert N, Rauch S. Localization of syntactic comprehension by positron emission tomography. Brain Lang 1996; 52: 452-73.

[21] Embick D, Marantz A, Miyashita Y, O'Neil W, Sakai KL. A syntactic specialization for Broca's area. Proc Natl Acad Sci USA 2000; 97: 6150-4.

[22] Moro A, Tettamanti M, Perani D, et al. Syntax and the brain: disentangling grammar by selective anomalies. Neuroimage 2001; 13: 110-8.

[23] Hashimoto R, Sakai KL. Specialisation in the left prefrontal cortex for sentence comprehension. Neuron 2002; 35: 589-97.

[24] Sakai KL. Language acquisition and brain development. Science 2005; 310: 815-9.

[25] Kinno R, Kawamura M, Shioda S, Sakai KL. Neural correlates of noncanonical syntactic processing revealed by a picture-sentence matching task. Hum Brain Mapp 2008; 29: 1015-27.

[26] Kinno R, Muragaki Y, Hori T, et al. Agrammatic comprehension caused by a glioma in the left frontal cortex. Brain Lang 2009; 110 : 71-80.

[27] Mazoyer BM, Tzourio N, Frak V, et al. The cortical representation of speech. J Cogn Neurosci 1993; 5: 467-79.

[28] Stowe LA, Broere CA, Paans AM, et al. Localising components of a complex task: Sentence processing and working memory. Neuroreport 1998; 9: 2995-9.

[29] Bottini G, Corcoran R, Sterzi R, et al. The role of the right hemisphere in the interpretation of figurative aspects of language: A positron emission tomography study. Brain 1994; 117: 1241-53.

[30] Friederici AD, Meyer M, von Cramon DY. Auditory language comprehension: An event-related fMRI study on the processing of syntactic and lexical information. Brain Lang 2000; 75: 465-77.

[31] Stowe LA, Haverkort M, Zwarts F. Rethinking the neurological basis of language. Lingua 2005; 115: 997-1042.

[32] Binkofski F, Amunts K, Stephan KM, et al. Broca's region subserves imagery of motion: A combined cytoarchitectonic and fMRI study. Hum Brain Mapp 2000; 11: 273-85.

[33] Kroger JK, Sabb FW, Fales CL, et al. Recruitment of anterior dorsolateral prefrontal cortex in human reasoning: a parametric study of relational complexity. Cereb Cortex 2002; 12: 477-85.

[34] Ben-Shachar M, Hendler T, Kahn I, Ben-Bashat D, Grodzinsky Y. The neural reality of syntactic transformations: Evidence from functional magnetic resonance imaging. Psychol Sci 2003; 14: 43340.

[35] Ben-Shachar M, Palti D, Grodzinsky Y. Neural correlates of syntactic movement: Converging evidence from two fMRI experiments. Neuroimage 2004; 21: 1320-36.

[36] Santi A, Grodzinsky Y. Working memory and syntax interact in Broca's area. NeuroImage 2007; 37: 8-17. 
[37] Santi A, Grodzinsky Y. Taxing working memory with syntax: Bihemispheric modulations. Hum Brain Mapp 2007; 28: 1089-97.

[38] Brodmann K. Vergleichende Lokalisationslehre der Großhirnrinde. Leipzig: J.A. Barth; 1909.

[39] Amunts K, Shleicher A, Burger U, et al. Broca's region revisited: cytoarchitecture and intersubject variability. J Comp Neurol 1999; 412: 319-41.

[40] Amunts K, Zilles K. In: Grodzinsky Y, Amunts K, Eds. Broca's region. New York: Oxford University Press 2006; pp. 17-30.

[41] Santi A, Grodzinsky Y. fMRI adaptation dissociates syntactic complexity dimensions. Neuroimage 2010; 51: 1285-93.

[42] Friederici AD. Processing local transitions versus long-distance syntactic hierarchies. Trends Cogn Sci 2004; 8: 245-7.

[43] Friederici AD. Pathways to language: fiber tracts in the human brain. Trends Cogn Sci 2009; 13: 175-81.

[44] Röder B, Stock O, Neville H, Bien S, Rösler F. Brain activation modulated by the comprehension of normal and pseudo-word sentences of different processing demands: a functional magnetic resonance imaging study. Neuroimage 2002; 15: 1003-14.

[45] Bornkessel I, Zysset S, Friederici AD, von Cramon DY, Schlesewsky M. Who did what to whom? The neural basis of argument hierarchies during language comprehension. Neuroimage 2005; 26: 221-33.

[46] Grewe T, Bornkessell L, Zysset S, et al. The emergence of the unmarked: A new perspective on the language-specific function of Broca's area. Hum Brain Mapp 2005; 26: 178-90.

[47] Grewe T, Bornkessell L, Zysset S, et al. Linguistic prominence and Broca's area: The influence of animacy as a linearization principle. Neuroimage 2006; 32: 1395-402.

[48] Friederici AD, Fiebach CJ, Schlesewsky M, Bornkessel I, von Cramon DY. Processing linguistic complexity and grammaticality in the left frontal cortex. Cereb Cortex 2006; 16: 1709-17.

[49] Bornkessel-Schlesewsky I, Schlesewsky M, von Cramon DY. Word order and Broca's region: Evidence for a supra-syntactic perspective. Brain Lang 2009; 111: 125-39.

[50] Friederici AD, Rüschemeyer S-A, Fiebach CJ, Hahne A. The role of left inferior frontal and superior temporal cortex in sentence comprehension: localizing syntactic and semantic processes. Cereb Cortex 2003; 13: 1047-3211.

[51] Fiebach CJ, Schlesewsky M, Bornkessel I, Friederici AD. In: Carreiras M, Clifton C Jr, Eds. The on-line study of sentence comprehension. New York: Psychology Press 2004; 357-70.

[52] Fitch WT, Hauser MD. Computational constraints on syntactic processing in a nonhuman primate. Science 2004; 303: 377-80.

[53] Bahlmann J, Schubotz RI, Friederici AD. Hierarchical artificial grammar processing engages Broca's area. Neuroimage 2008; 42: 525-34.

[54] Makuuchi M, Bahlmann J, Anwander A, Friederici AD. Segregating the core computational faculty of human language from working memory. Proc Natl Acad Sci USA 2009; 106: 83627.

[55] Konieczny L. Locality and parsing complexity. J Psycholinguist Res 2000; 29: 627-45.

[56] Vasishth S, Lewis RL. Argument-head distance and processing complexity: Explaining both locality and antilocality effects. Language 2006; 82: 767-94.

[57] Gibson E. Linguistic complexity: Locality of syntactic dependencies. Cognition 1998; 68: 1-76.

[58] Gibson E. In: Miyashita Y, Marantz A, O'Neil W, Eds. Image, language, brain. Cambridge, MA: MIT Press 2000; 95-126.

[59] Lewis RL, Vasishth S. An activation-based model of sentence processing as skilled memory retrieval. Cogn Sci 2005; 29: 1-45.

[60] Lewis RL, Vasishth S, Van Dyke JA. Computational principles of working memory in sentence comprehension. Trends Cogn Sci 2006; 10: 447-54

[61] McElree B, Foraker S, Dyer L. Memory structures that subserve sentence comprehension. J Mem Lang 2003; 48: 67-91.

[62] Martin AE, McElree B. A content-addressable pointer mechanism underlies comprehension of verb-phrase ellipsis. J Mem Lang 2008; 58: 879-906.

[63] Chomsky N. The Minimalist Program. Cambridge, MA: MIT Press 1995.

[64] Kayne RS. Connectedness and Binary Branching. Dordrecht: Foris 1984.

[65] Haegeman L. Introduction to Government and Binding Theory. Oxford: Blackwell 1994.
[66] Chomsky N. Lectures on government and binding. Dordrecht: Kluwer 1981.

[67] Van Valin RD Jr. Exploring the Syntax-Semantics Interface. Cambridge: Cambridge University Press 2005.

[68] Bresnan J. Lexical Functional Grammar. Oxford: Blackwell 2001

[69] Hagoort P. How the brain solves the binding problem for language: A neurocomputational model of syntactic processing. Neuroimage 2003; 20: S18-S29.

[70] Hagoort P. On Broca, brain, and binding: a new framework. Trends Cogn Sci 2005; 9: 416-23.

[71] Pollard C, Sag I. Head-driven phrase structure grammar. Chicago: University of Chicago Press 1994.

[72] Hagoort P, Baggio G, Willems RM. In: Gazzaniga MS, Ed. The cognitive neurosciences. Cambridge, MA: MIT Press 2009; 81936 .

[73] Schubotz RI, von Cramon DY. Sequences of abstract nonbiological stimuli share ventral premotor cortex with action observation and imagery. J Neurosci 2004; 24: 5467-74.

[74] Schubotz RI. Prediction of external events with our motor system: towards a new framework. Trends Cogn Sci 2007; 11:211-8.

[75] Haider H. Symmetry breaking in syntax. Cambridge: Cambridge University Press 2012.

[76] Greenfield PM. Language, tools and brain: The ontogeny and phylogeny of hierarchically organized sequential behavior. Behav Brain Sci 1991; 14: 531-95.

[77] Fadiga L, Craighero L, D'Ausilio A. Broca's area in language, action, and music. Ann N Y Acad Sci 2009; 1169: 448-58.

[78] Thompson-Schill SL, D'Esposito M, Aguirre GK, Farah MJ. Role of left inferior prefrontal cortex in retrieval of semantic knowledge: a reevaluation. Proc Natl Acad Sci USA 1997; 94: 14792-7.

[79] Thompson-Schill SL, Bedny M, Goldberg RF. The frontal lobes and the regulation of mental activity. Curr Opin Neurobiol 2005; 15: 219-24

[80] Novick JM, Trueswell JC, Thompson-Schill SL. Cognitive control and parsing: Reexamining the role of Broca's area in sentence comprehension. Cogn Aff Behav Neurosci 2005; 5: 263-81.

[81] Thothathiri M, Schwartz MF, Thompson-Schill SL. Selection for position: The role of left ventrolateral prefrontal cortex in sequencing language. Brain Lang 2010; 113: 28-38.

[82] January D, Trueswell JC, Thompson-Schill SL. Co-localization of Stroop and syntactic ambiguity resolution in Broca's area: Implications for the neural basis of sentence processing. J Cogn Neurosci 2009; 21: 2434-44.

[83] Stroop JR. Studies of interference in serial verbal reactions. J Exp Psychol 1935; 18: 643-62.

[84] Caplan D, Alpert N, Waters G, Olivieri A. Activation of Broca's area by syntactic processing under conditions of concurrent articulation. Hum Brain Mapp 2000; 9: 65-71.

[85] Kaan E, Swaab TY. The brain circuitry of syntactic comprehension. Trends Cogn Sci 2002; 6: 350-6.

[86] Müller R-A, Basho S. Are nonlinguistic functions in "Broca's area" prerequisites for language acquisition? FMRI findings from an ontogenetic viewpoint. Brain Lang 2004; 89: 329-36.

[87] Fiebach CJ, Vos SH, Friederici AD. Neural correlates of syntactic ambiguity in sentence comprehension for low and high span readers. J Cogn Neurosci 2004; 16: 1562-75.

[88] Fiebach CJ, Schlesewsky M, Lohmann G, von Cramon DY, Friederici AD. Revisiting the role of Broca's area in sentence processing: Syntactic integration versus syntactic working memory. Hum Brain Mapp 2005; 24: 79-91.

[89] Chen E, West WC, Waters G, Caplan D. Determinants of BOLD signal correlates of processing object-extracted relative clauses. Cortex 2006; 42: 591-604.

[90] Grodzinsky Y, Friederici AD. Neuroimaging of syntax and syntactic processing. Curr Opin Neurobiol 2006; 16: 240-6.

[91] Bornkessel-Schlesewsky I, Schlesewsky M. Processing syntax and morphology: A neurocognitive perspective. Oxford: Oxford University Press 2009

[92] McElree B. In: Ross BH, Ed. The psychology of learning and motivation. San Diego CA: Academic Press 2006; 155-200.

[93] Jonides J, Lewis RL, Nee DE, et al. The mind and brain of shortterm memory. Annu Rev Psychol 2008; 59: 193-224.

[94] Vosse T, Kempen GAM. Syntactic assembly in human parsing: A computational model based on competitive inhibition and lexicalist grammar. Cognition 2000; 75: 105-43. 
[95] Lenerz J. Zur Abfolge nominaler Satzglieder im Deutschen. Tübingen: Gunter Narr Verlag 1977.

[96] Müller G. Optimality, markedness and word order in German. Linguistics 1999; 37: 777-818.

[97] Bahlmann J, Rodriguez-Fornells A, Rotte M, Münte TF. An fMRI study of canonical and noncanonical word order in German. Hum Brain Mapp 2007; 28: pp. 940-9.

[98] Frey W. In: Späth A, Eds. Interfaces and interface conditions. Berlin: Walter de Gruyter 2007; 329-48.

[99] Keenan EL. In: Li CN, Ed. Subject and topic. New York: Academic Press 1976; pp. 303-33.

[100] Tomlin RS. Basic word order: Functional principles. London: Routledge (Croom Helm) 1986.

[101] Comrie B. Linguistic universals and language typology. Oxford: Blackwell 1989.

[102] Croft W. Typology and universals. $2^{\text {nd }}$ ed. Cambridge: Cambridge University Press 2003.

[103] Bossong G. Differentielle Objektmarkierung in den neuiranischen Sprachen [ $=$ Differential object marking in the New Iranian languages]. Tübingen: Narr 1985.

[104] Aissen J. Differential object marking: Iconicity vs. economy. Nat Lang Ling Theory 2003; 21: 435-83.

[105] Silverstein M. In: Dixon RMW, Ed. Grammatical categories in Australian languages. New Jersey: Humanities Press 1976; 112-71.

[106] de Swart P. Cross-linguistic variation in object marking. Utrecht: Netherlands Graduate School of Linguistics (LOT) 2007.
[107] Bornkessel-Schlesewsky I, Schlesewsky M. The role of prominence information in the real time comprehension of transitive constructions: a cross-linguistic approach. Lang Ling Compass 2009; 3: 19-58.

[108] Kouneiher F, Charron S, Koechlin E. Motivation and cognitive control in the human prefrontal cortex. Nat Neurosci 2009; 12 : 939-47.

[109] Bisang W. Precategoriality and syntax-based parts of speech: The case of Late Archaic Chinese. Studies Lang 2008; 32: 568-89.

[110] Luke K-K, Liu H-L, Wai Y-Y, Wan Y-L, Tan LH. Functional anatomy of syntactic and semantic processing in language comprehension. Hum Brain Mapp 2002; 16: 133-45.

[111] Hawkins JA. A performance theory of order and constituency. Cambridge: Cambridge University Press 1994.

[112] Inui $\mathrm{T}$, Otsu $\mathrm{Y}$, Tanaka $\mathrm{S}$, et al. A functional MRI analysis of comprehension processes of Japanese sentences. Neuro Rep 1998; 9: 3325-8.

[113] Erguvanlı EE. The function of word order in Turkish grammar. Berkeley/Los Angeles/London: University of California Press 1984.

[114] Gentner TQ, Fenn KM, Margoliash D, Nusbaum HC. Recursive syntactic pattern learning in songbirds. Nature 2006; 440: 1204-7.

[115] Montague R. Linguaggi nella societa e nella tecnica. In: Visentini B, Ed. Milan 1970; pp. 189-224.

[116] Montague R. Formal Philosophy. Selected Papers of Richard Montague. New Haven, CT: Yale University Press 1974.

(C) Bornkessel-Schlesewsky and Schlesewsky; Licensee Bentham Open.

This is an open access article licensed under the terms of the Creative Commons Attribution Non-Commercial License (http://creativecommons.org/ licenses/by-nc/3.0/), which permits unrestricted, non-commercial use, distribution and reproduction in any medium, provided the work is properly cited. 